\title{
Impact of patient-accessible electronic medical records in rheumatology: use, satisfaction and effects on empowerment among patients
}

Rosalie van der Vaart ${ }^{1}$, Constance HC Drossaert ${ }^{1}$, Erik Taal ${ }^{1}$, K Wiepke Drossaers-Bakker ${ }^{2}$, Harald E Vonkeman ${ }^{1,2}$ and Mart AFJ van de Laar ${ }^{1,2}$

\begin{abstract}
Background: To measure the use, satisfaction and impact of a web portal which provides patients with rheumatoid arthritis home access to their electronic medical records (EMR).

Methods: A pretest-posttest study was conducted among 360 patients. Questionnaires assessed socio-demographics, health literacy, Internet use, disease characteristics, patient-provider relationship and empowerment before and after launching a hospital-based patient web portal. To measure the impact of the portal, patients' satisfaction with care, trust in their rheumatologist, self-efficacy in patient-provider communication, illness perceptions, and medication adherence were assessed. The post-test included questions on portal use, satisfaction, and self-perceived impact due to portal use.

Results: $54 \%$ of respondents with Internet access had viewed their EMR. Respondents were positive about the ease of use and usefulness of the portal and reported very few problems. Age $(P=.03)$, amount of Internet use $(P=.01)$ and self-perceived Internet skills $(P=.03)$ significantly predicted portal use. Of the respondents who had logged in, 44\% reported feeling more involved in their treatment and 37\% felt they had more knowledge about their treatment. Significant differences over time were not found on the empowerment-related instruments.

Conclusions: The current portal succeeded in offering patients access to their EMR in a usable and understandable way. While its true impact is difficult to grasp, a relevant portion of the patients felt more involved in their treatment due to the web portal. Offering patients home EMR access, therefore, appears to be a valuable addition to the care process.
\end{abstract}

Keywords: Electronic Medical Record, Web portal, Patient access, Patient empowerment, eHealth

\section{Background}

Since many rheumatic diseases are chronic and can have a large impact on patients' lives, it is essential that patients become involved in their treatment and have proper selfcare practices [1,2]. Increasing patients' responsibilities and autonomy is also essential for the redesign of health services, from current disease- or institutional-centered models to patient-centered models of care, in order to keep expenses under control [3,4]. The implementation of information and communication technologies in health care can play an essential role in this shift [5]. A slowly

\footnotetext{
* Correspondence: r.vandervaart@fsw.leidenuniv.nl

${ }^{1}$ Department of Psychology, Health \& Technology, University of Twente,

Citadel H423, P.O. Box 2177500 AE, Enschede, The Netherlands

Full list of author information is available at the end of the article
}

emerging technology in health care is the ability to provide patients online home-access to their electronic medical records (EMRs), via hospital-based patient web portals $[6,7]$. The key benefit of this application is that patients can (repeatedly) read the documentation on their disease and treatment, at home, which has the potential to empower patients in their care process $[8,9]$.

Providing patients home EMR-access may influence health care on several levels. First of all, it increases transparency of medical data, which could reduce medical errors, increase patients' trust in care providers and could enhance patient satisfaction [10-12]. Secondly, patients' knowledge and understanding of the disease and treatment may be enhanced [13], increasing their involvement in decision making processes $[13,14]$. Thirdly, patients

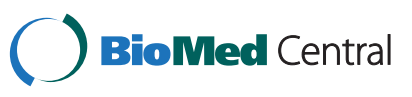


may feel more control over their disease and treatment, which could positively influence treatment adherence [15], and even clinical outcomes [16].

While patient access to medical records could benefit health care, an online application might not suit everyone. Previous studies have shown that users of online applications are often relatively young and highly educated [17]. Furthermore, patients' abilities to use (online) health information, also called "health literacy" is assumed to be related to acceptance of online applications [18]. Until now, little is known about the predictors for using home access to medical records or on the difficulties that patients experience when using this service.

Hospitals increasingly offer patients home access to their EMR, but to the best of our knowledge, no studies have thus far been conducted in the field of rheumatology. Still, previous studies have shown that patients are indeed interested in this option $[19,20]$, and both rheumatologists and nurses believe that it could have a positive impact on the empowerment of their patients [21]. Based upon these studies, a web portal was designed following user-centered design principles [22], which offers information on rheumatic diseases, treatments, and available aids and support (www.reumacentrumtwente.nl). Additionally, the patient web portal contains a personal secure login section, where patients can find their diagnosis, current medication and medication history, blood results, actual and previous disease activity, and outcomes on quality of life related instruments. All data is accompanied by written information and (where possible) charts and graphs to show the fluctuation in scores along a timeline using colors to compare the data to norm scores. A screenshot of one of the patient web portal pages can be found in Figure 1. The purpose of this study was to assess the use, satisfaction, and the impact of the portal on the patient-provider relationship and patient empowerment, among patients suffering from rheumatoid arthritis.

\section{Methods}

A pretest-posttest design was used, conducting a survey in the month before the web portal went online (T0), and five months after (T1).

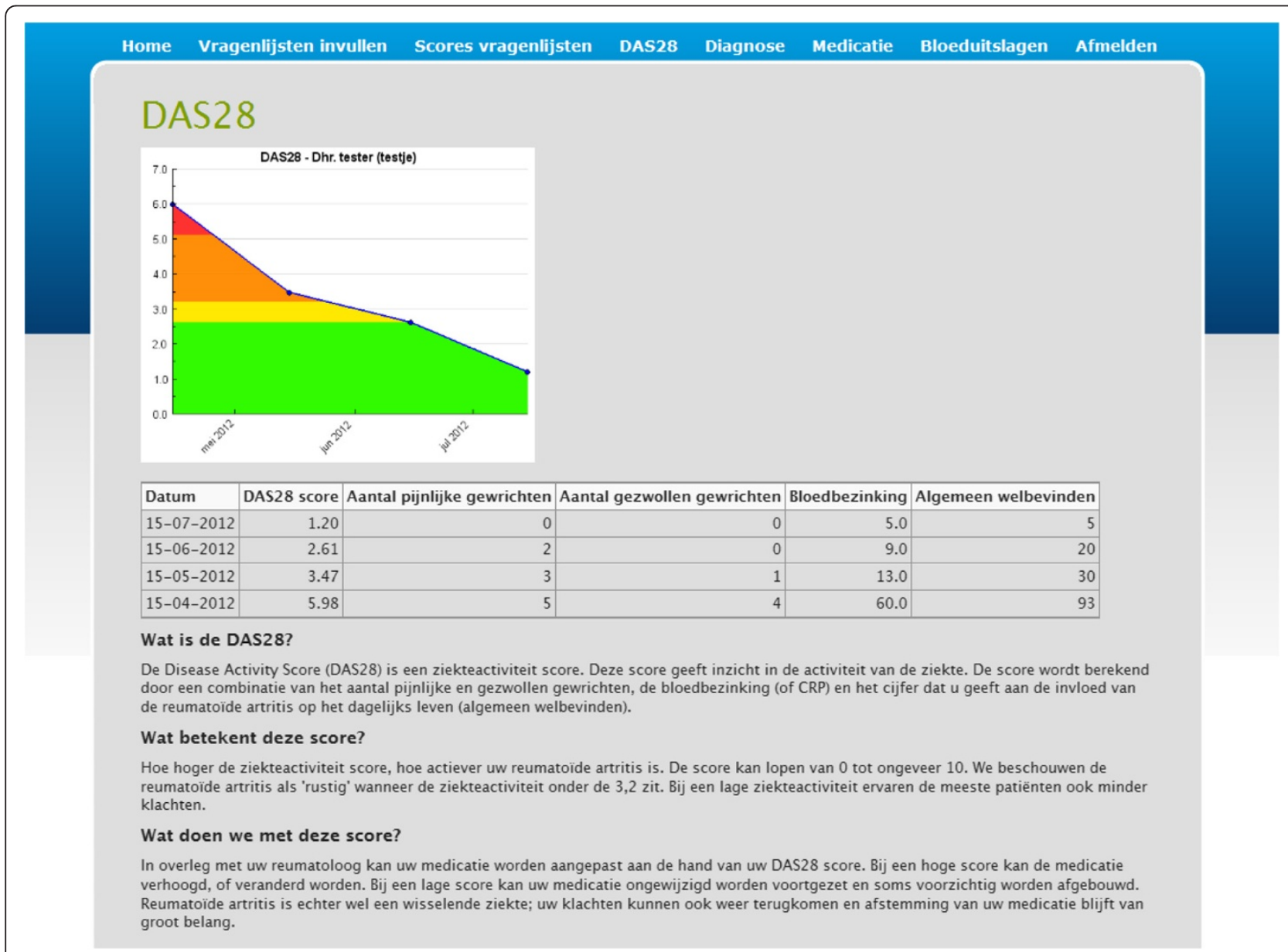

Figure 1 Screenshot of a login page providing rheumatoid arthritis disease activity (DAS28) scores with an explanation of the data. 


\section{Patients and procedure}

In total, 415 patients diagnosed with RA, conform the 1987 American College of Rheumatology classification criteria, were selected from the patient database of the Arthritis Centre Twente in Enschede, the Netherlands. Treating rheumatologists $(n=6)$ were asked to exclude those patients from the selection who were deceased $(\mathrm{n}=10)$, or had had their last consultation longer than one year ago $(n=24)$. Other reasons for rheumatologists to exclude patients were: not diagnosed with RA $(n=3)$, severe co-morbidity $(n=4)$ or change of hospital $(n=1)$. In total, 42 patients were excluded. The 373 remaining patients were sent a personal invitation letter and a paper-and-pencil questionnaire on T0. A reminder was sent to those patients who did not respond within two weeks. One invitation was returned as undeliverable and 6 patients called or e-mailed to report that they were not interested in participation. After the pretest, all (but these 7) patients received an invitation to visit the portal and to $\log$ in with a personal account, which could be obtained in person in the clinic. Five months later, the same sample was approached with a personal letter and posttest questionnaire, with a reminder after 2 weeks, excluding the 7 patients that had withdrawn $(n=366)$. At $T 1$, four questionnaires were returned as undeliverable and two patients were deceased, resulting in 360 patients that received questionnaires on both $\mathrm{T} 0$ and $\mathrm{T} 1$. This study did not need approval of the ethical review board.

\section{Instruments}

To investigate predictors of patient web portal use, the questionnaire on T0 comprised of socio-demographics (age, gender, education level, marital status, and employment), health literacy [23,24], Internet use (access, quantity of use and self-perceived skills), and disease characteristics (moment of diagnosis, number of clinic visits in the past 6 months, self-perceived general health).

To investigate the impact of the patient web portal, five validated instruments were included on which change could be expected due to the use of the portal. Satisfaction with care was measured by items based on the QUOTE rheumatic patients [25]. Six items were used measuring satisfaction with the rheumatologist and the nurse practitioner, respectively. Response options ranged from "not at all" (1) to "definitely" (4). The possible range of scores for both scales was 6 to 24, with 24 representing a high satisfaction with care. Cronbach's alphas were .83 and .87 respectively. Trust in the rheumatologist was measured with the Trust In Physicians short form (TRIP_sf), which is based on the Cologne-Patient-Questionnaire scale "trust in physicians" and which measures different aspects of a trusting physician-patient-interaction [26]. Items could be answered using a 5-point Likert scale ranging from "do not agree at all" (1) to "completely agree" (5), with a possible score ranging from 5 to 20 , with 20 representing a high trust in the rheumatologist. Cronbach's alpha was .93. Self-efficacy in patient-provider communication was assessed with the 5-item version of the Perceived Efficacy in Patient-Physician Interactions questionnaire (PEPPI-5), which assesses the subjective sense of patients' confidence when interacting with their physicians [27]. The instrument has been translated and validated for the Dutch situation [28]. Participants respond to each question on a 5-point Likert scale ranging from "not at all confident" (1) to "very confident" (5). The range of possible scores is 5 to 25 , with 25 representing the highest patient self-efficacy. Cronbach's alpha of this instrument was .96 in our data. Illness perception was assessed with the Revised Illness Perception Questionnaire (IPQ-R). The subscales 'Personal control' (6 items), 'Treatment control' (5 items), and 'Illness coherence' (5 items) were used, which assess personal control and self-efficacy beliefs, belief in the treatment, and understanding of the illness, respectively [29]. All items can be answered on a 5point Likert scale ranging from "strongly disagree" (1) to "strongly agree" (5), which makes the possible range of scores $6-30$ and $5-25$, with 30 and 25 representing the highest perceived control. Cronbach's alphas of the subscales were .52, .72, and .76, respectively. Medication adherence was assessed with the Morisky Medication Adherence scale (MMA), which measures medicationtaking behavior using eight items. Response categories are yes/no for seven dichotomous items and a 5-point Likert response ranging from "always" (1) to "never" (5) for the last item, which was dichotomized [30,31]. Scores were recoded, so that higher scores represent a better medication adherence, with eight representing perfect adherence. Cronbach's alpha was .66.

The questionnaire on T1 comprised of the same measures as the pre-test, except for health literacy. To assess use and satisfaction with the patient web portal, several questions were added to the post-test, including: (1) use and moment of use of the website section and login section of the portal, (2) sharing of the personal information from the portal with others, (3) perceived ease of use, clarity, usefulness and completeness of the portal, (4) problems encountered on the portal, and what was done to solve them, (5) difficulties with understanding information in the login section, and (6) occurrence of wrong information in the login section. Additionally, questions were asked on the self-perceived impact of the portal. These questions covered the same constructs as the aforementioned instruments, but asked patients directly if they felt that the portal caused an increase, decrease, or did not change anything concerning these outcomes. 


\section{Data analysis}

Analyses were performed using the Statistical Package for the Social Sciences (IBM SPSS Statistics 20). To analyze differences in age and gender at baseline between patients who did return the questionnaire at T0 and/or T1 and those who did not, the Mann-Whitney test was applied for age and the chi-square for gender. Descriptive statistics were used to summarize sociodemographics, Internet-related and disease characteristics, portal use and satisfaction, and perceived impact of the portal. To explore relationships between patient characteristics and portal usage (non-use, website only use, and login use), the Kruskal-Wallis test was applied for continuous variables and the chi-square for discrete variables. Whenever a significant difference was found, pairwise comparisons were performed to further analyze differences between groups, using Mann-Whitney or chi-square tests. Additionally, multi-nominal logistic regression was used to analyze which variables uniquely predicted patient web portal use. To analyze the effect of portal use, Analysis of Covariance was used, in which scores on $\mathrm{T} 1$ of non-users, website users and login users were compared, including their T0 scores as covariate. For all analyses, p-values $<0.01$ (two-tailed) were used as criterion for statistical significance, as multiple comparisons were executed.

\section{Results}

\section{Respondents}

Of the 372 patients who received the questionnaire at T0, 259 (70\%) sent it back completed. At T1, 360 patients were sent the questionnaire, of which 214 (59\%) completed it. A total of 194 (54\%) patients completed both questionnaires. There were no differences in age or gender between responders and non-responders on T0. At T1 and in the paired samples, there were no differences between responders and non-responders in gender, but the mean age of responders was 4.2 years higher $(P=.01)$ and 3.6 years higher $(P=.02)$, respectively.

\section{Patient web portal use}

Of all respondents on T1, more than half (54\%) reported to have used the portal, and 86 respondents (40\%) reported to have logged in to view their personal information (Table 1). Of all respondents with Internet access, $70 \%$ had used the portal and 54\% had logged in. Lack of Internet access was the most frequent reason for not using the portal $(n=56)$. Other reasons not to have used the portal were: "I planned to but didn't have time yet" $(\mathrm{n}=30)$, "I'm not interested" $(\mathrm{n}=19)$, "I tried, but something went wrong" $(n=7)$, and "I don't know how to visit the portal" $(\mathrm{n}=5)$.

Of the respondents who logged in on the portal, 60 (70\%) reported to do this in the week before a consultation
Table 1 Patient web portal usage of respondents at T1 ( $n=214)$

\begin{tabular}{|c|c|c|c|c|}
\hline \multirow[t]{2}{*}{ Patient web portal use } & \multicolumn{2}{|c|}{$\begin{array}{l}\text { All respondents } \\
(n=214)\end{array}$} & \multicolumn{2}{|c|}{$\begin{array}{l}\text { Respondents } \\
\text { with home } \\
\text { Internet access } \\
(\mathrm{n}=158)\end{array}$} \\
\hline & $\mathrm{n}$ & $(\%)$ & $n$ & $(\%)$ \\
\hline $\begin{array}{l}\text { Respondents who used the web } \\
\text { portal }\end{array}$ & 115 & $(54)$ & 111 & (70) \\
\hline 1 time & 41 & (19) & 38 & (24) \\
\hline 2 times & 47 & $(22)$ & 46 & (29) \\
\hline 3 times or more & 27 & (13) & 27 & (17) \\
\hline $\begin{array}{l}\text { Respondents who used the website } \\
\text { only }\end{array}$ & 29 & $(14)$ & 26 & (16) \\
\hline Respondents who logged in & 86 & $(40)$ & 85 & $(54)$ \\
\hline
\end{tabular}

with their rheumatologist or nurse practitioner. Sixteen respondents (19\%) reported doing this after their consultation (data not shown in Table). Of the respondents who logged in on the portal, 29 (34\%) shared their personal information with a family member.

\section{Predictors of patient web portal use}

Table 2 shows the personal and Internet-related characteristics of the respondents at $\mathrm{T} 1$. The overall mean age was $62(\mathrm{SD}=13.3)$, ranging from 20 to 86 years old. Two thirds of the respondents were female, which is representative for our population. Overall, respondents reported using the Internet regularly, but only a minority (31\%) rated their own Internet skills as "good" to "very good". Univariate analyses showed that age, marital status, education level, employment, health literacy and all Internetrelated characteristics were significantly related to portal usage. Non users were more often older, single, lower educated and unemployed. Respondents with a higher level of health literacy were more inclined to log in on the portal, as well as respondents who used the Internet more often, had more years of experience, and perceived their own skills as better.

Table 3 shows an overview of health-related characteristics of the respondents on T1. Most patients had been diagnosed with RA for more than a year, and visited the rheumatology clinic regularly. The majority of respondents perceived their general health as good or excellent. None of these characteristics were significantly related to portal use.

Further analyses with multi-nominal logistic regression, showed that all variables together explained $59 \%$ of the variance $\left(\mathrm{R}^{2}=.59\right.$ (Nagelkerke), model $\chi^{2}(22)=94.04$, $P<.001)$. Patient web portal use was significantly predicted by age $\left(b=.09\right.$, Wald $\left.X^{2}(1)=4.72, P=.03\right)$, with younger respondents being more inclined to use the portal. Logging in at the portal was significantly predicted by self-perceived Internet skills $\left(b=-.96\right.$, Wald $\chi^{2}(1)=4.74$, 
Table 2 Personal and Internet-related characteristics of respondents on T1 and differences between patient web portal users and non-users $(n=214)$

\begin{tabular}{|c|c|c|c|c|c|}
\hline Characteristic & Total $(n=214)$ & Non-users $(n=99)$ & Website users $(n=29)$ & Login users $(n=86)$ & $P^{1}$ \\
\hline Age (M, (SD)) & $62(13.2)$ & $66(14)^{\mathrm{ac}}$ & $63(11)^{\mathrm{ab}}$ & $56(11)^{b c}$ & .000 \\
\hline Gender (\% female) & $140(65 \%)$ & $69(70 \%)$ & $14(48 \%)$ & $57(66 \%)$ & n.s. \\
\hline Marital status (\% living together) & $170(80 \%)$ & $68(70 \%)^{\mathrm{ac}}$ & $26(90 \%)^{\mathrm{a}}$ & $76(88 \%)^{c}$ & .000 \\
\hline \multicolumn{6}{|l|}{ Education level } \\
\hline low & $86(40 \%)$ & $54(55 \%)^{\mathrm{ac}}$ & $8(28 \%) a$ & $24(28 \%)^{c}$ & \multirow[t]{4}{*}{.001} \\
\hline medium & $89(42 \%)$ & $29(29 \%)$ & $15(52 \%)$ & $45(52 \%)$ & \\
\hline high & $33(15 \%)$ & $11(11 \%)$ & $6(21 \%)$ & $16(19 \%)$ & \\
\hline missing & $6(3 \%)$ & $4(4 \%)$ & - & $1(1 \%)$ & \\
\hline Employment (\% working) & $72(34 \%)$ & $24(24 \%)^{c}$ & $10(34 \%)$ & $38(44 \%)^{c}$ & .02 \\
\hline Health literacy $(M(S D))(n=157)^{2}$ & $38.6(7.2)$ & $36.5(7.6)^{c}$ & $37.9(7.2)$ & $40.9(6.1)^{c}$ & .001 \\
\hline \multicolumn{6}{|l|}{ Internet-related } \\
\hline \multicolumn{6}{|l|}{ Amount of Internet use } \\
\hline Daily/several days a week & $117(55 \%)$ & $27(27 \%)^{c}$ & $17(59 \%)^{\mathrm{b}}$ & $73(85 \%)^{c b}$ & \multirow[t]{3}{*}{.000} \\
\hline One day a week or less & $50(23 \%)$ & $30(30 \%)$ & $9(31 \%)$ & $11(13 \%)$ & \\
\hline Missing (no home Internet access) & $47(22 \%)$ & $43(43 \%)$ & $3(10 \%)$ & $1(1 \%)$ & \\
\hline \multicolumn{6}{|l|}{ Years of Internet experience } \\
\hline$<5$ years & $44(21 \%)$ & $21(21 \%)^{c}$ & $10(34 \%)^{b}$ & $13(15 \%)^{\mathrm{cb}}$ & \multirow[t]{3}{*}{.001} \\
\hline$\geq 5$ years & $113(53 \%)$ & $26(26 \%)$ & $16(55 \%)$ & $71(83 \%)$ & \\
\hline Missing & $57(27 \%)$ & $52(53 \%)$ & $3(10 \%)$ & $2(2 \%)$ & \\
\hline \multicolumn{6}{|l|}{ Self-perceived Internet skills } \\
\hline Good to very good & $66(31 \%)$ & $11(11 \%)^{c}$ & $6(21 \%)^{b}$ & $49(57 \%)^{\mathrm{cb}}$ & \multirow[t]{4}{*}{.000} \\
\hline Average to reasonable & $75(35 \%)$ & $28(28 \%)$ & $16(55 \%)$ & $31(36 \%)$ & \\
\hline Poor & $22(10 \%)$ & $13(13 \%)$ & $5(17 \%)$ & $4(5 \%)$ & \\
\hline Missing & $51(24 \%)$ & 47 (47\%) & $2(7 \%)$ & $2(2 \%)$ & \\
\hline
\end{tabular}

${ }^{1}$ Kruskal-Wallis or Chi-square tests.

${ }^{2}$ Scale ranges from 14 (low level of health literacy) to 56 (high level of health literacy); data from T0.

${ }^{a}$ Significant difference between non-users and website users.

${ }^{\text {b}}$ Significant difference between website users and login users.

'Significant difference between non-users and login users.

$P=.03)$ and amount of Internet use $\left(b=-.70\right.$, Wald $\chi^{2}$ $(1)=6.07, P=.01)$.

\section{Satisfaction with the patient web portal}

The portal was positively appraised and most login users found their personal information "fairly easy" to "very easy" to understand (Table 4). When logging in to the portal, 15 respondents experienced a single problem. As a result, three respondents left the portal, three asked for help, and nine kept trying until they succeeded. Two respondents reported reoccurring problems when logging in to the portal. One of them requested a new account, and one called the web host. Nine respondents who had logged in to the portal reported finding incorrect information. In all cases, this concerned medication or blood test information that was outdated. Three respondents mentioned this during a consultation with their doctor and one participant called the hospital.
Five respondents reported not taking any action (yet) because: "I thought it wasn't important", "I didn't know who to contact", and "I was too insecure to contact anyone".

\section{Subjective impact of the patient web portal}

Several positive changes were perceived by patients who had logged on to the portal (Table 5). A large part of the respondents felt that they were more involved in their treatment and that they understood their treatment better due to the patient web portal. One third of all login users felt that the quality of care was higher as a result of the portal. Also, according to a large part of the respondents, knowledge about the disease, understanding of what care providers explain, communication with the care providers, and trust in the care providers was increased. Additionally, some patients reported to search less for health information by themselves, as a result of 
Table 3 Health-related characteristics of respondents at T1 and differences between portal users and non-users ( $n=214)$

\begin{tabular}{|c|c|c|c|c|c|}
\hline Characteristics & Total $(n=214)$ & Non-users $(n=99)$ & Website users $(n=29)$ & Login users $(n=86)$ & $P^{1}$ \\
\hline \multicolumn{6}{|l|}{ Time since diagnosis } \\
\hline$<5$ years ago & $150(70 \%)$ & $67(68 \%)$ & $22(76 \%)$ & $61(71 \%)$ & n.s. \\
\hline$\geq 5$ years ago & $60(28 \%)$ & $28(28 \%)$ & $7(24 \%)$ & $25(29 \%)$ & \\
\hline missing & $4(2 \%)$ & $4(4 \%)$ & - & - & \\
\hline \multicolumn{6}{|c|}{ Number of clinic visits in the past 6 months } \\
\hline $0-1$ & $66(31 \%)$ & $36(36 \%)$ & $8(28 \%)$ & $22(26 \%)$ & n.s. \\
\hline 2 & $118(55 \%)$ & $53(54 \%)$ & $16(55 \%)$ & 49 (57\%) & \\
\hline 3 or more & $23(11 \%)$ & $5(5 \%)$ & $4(14 \%)$ & $14(16 \%)$ & \\
\hline Missing & $7(3 \%)$ & $5(5 \%)$ & $1(3 \%)$ & $1(1 \%)$ & \\
\hline \multicolumn{6}{|c|}{ Self-perceived general health } \\
\hline Good to excellent & $126(59 \%)$ & $54(55 \%)$ & $20(69 \%)$ & $52(60 \%)$ & n.s. \\
\hline Reasonable to poor & $86(40 \%)$ & $43(43 \%)$ & $9(31 \%)$ & $34(40 \%)$ & \\
\hline Missing & $2(1 \%)$ & $2(2 \%)$ & - & - & \\
\hline
\end{tabular}

${ }^{1}$ Chi-square tests.

the information provided by the hospital-based portal. Only one participant perceived a negative change, he/ she felt less involved in the treatment due to the patient web portal. No further adverse effects were reported by the participants.

Pre-post test results on impact of the patient web portal Analyses of Covariance revealed that the T1 scores on the impact outcome measures did not differ among the three groups (non-users, website only users and login users) (Table 6). Website users and login users did not show a larger improvement in the patient-provider

Table 4 Appraisal, comprehension and accuracy of the login part of the patient web portal $(n=86)$

\begin{tabular}{|c|c|c|}
\hline & M (S.D.) & n (\%) \\
\hline \multicolumn{3}{|l|}{ Appraisal of the login part $(n=64-75)^{1}$} \\
\hline Ease of use & $4.4(.8)$ & \\
\hline Clarity & $4.3(.7)$ & \\
\hline Usefulness & $4.3(.7)$ & \\
\hline Completeness & $4.1(.9)$ & \\
\hline \multicolumn{3}{|l|}{ Comprehension of the login pages $(n=63-72)^{2}$} \\
\hline DAS28 (disease activity) & $3.4(.7)$ & \\
\hline Medication (history) & $3.5(.6)$ & \\
\hline Blood results & $3.5(.5)$ & \\
\hline Feedback on monitored data & $3.5(.6)$ & \\
\hline \multicolumn{3}{|c|}{ Encountered problems when logging in on the patient web portal } \\
\hline 1 problem & & $15(17)$ \\
\hline 2 problems & & $2(2)$ \\
\hline Found incorrect (our-of-date) information & & $9(10)$ \\
\hline
\end{tabular}

${ }^{1}$ Answer options ranged from 1 (very negative) to 5 (very positive).

${ }^{2}$ Answer options ranged from 1 (very difficult) to 4 (very easy). relationship and on empowerment than non-users did, as we would have expected. It should be noted, however, that ceiling effects at $\mathrm{T} 0$ were found for four out of eight outcome measures. A ceiling effect is present when at least $15 \%$ of respondents scored the highest possible

Table 5 Perceived impact of the patient web portal according to users $(n=115)$

\begin{tabular}{|c|c|c|}
\hline Empowerment-related variables & $\begin{array}{l}\text { Website users } \\
(\mathrm{n}=29) \mathrm{n}(\%)\end{array}$ & $\begin{array}{l}\text { Login users } \\
(n=86) n(\%)\end{array}$ \\
\hline \multicolumn{3}{|l|}{$\begin{array}{l}\text { Using the patient web portal increased } \\
\text { my ... }\end{array}$} \\
\hline Involvement in the treatment & $1(3 \%)$ & $38(44 \%)$ \\
\hline Knowledge about the treatment & $2(7 \%)$ & $32(37 \%)$ \\
\hline Quality of care & $2(7 \%)$ & 25 (29\%) \\
\hline Knowledge about the disease & $2(7 \%)$ & $21(24 \%)$ \\
\hline $\begin{array}{l}\text { Understanding of what care } \\
\text { providers explain }\end{array}$ & - & $21(24 \%)$ \\
\hline $\begin{array}{l}\text { Self-efficacy in communication with } \\
\text { care providers }\end{array}$ & - & $16(19 \%)$ \\
\hline Trust in my care provider & - & $14(16 \%)$ \\
\hline $\begin{array}{l}\text { Insight into the need of medication } \\
\text { therapy }\end{array}$ & $1(3 \%)$ & $12(14 \%)$ \\
\hline Medication adherence & - & $8(9 \%)$ \\
\hline $\begin{array}{l}\text { Communication with others about } \\
\text { my disease }\end{array}$ & - & $6(7 \%)$ \\
\hline $\begin{array}{l}\text { Number of online searches for } \\
\text { health information }\end{array}$ & - & $4(5 \%)$ \\
\hline \multicolumn{3}{|l|}{$\begin{array}{l}\text { Using the patient web portal decreased } \\
\text { my ... }\end{array}$} \\
\hline $\begin{array}{l}\text { Number of online searches for } \\
\text { health information }\end{array}$ & - & $15(17 \%)$ \\
\hline Worries about my health & $1(3 \%)$ & $3(3 \%)$ \\
\hline Involvement in the treatment & - & $1(1 \%)$ \\
\hline
\end{tabular}


Table 6 Effects of the website and login part on empowerment-related outcomes $(n=214)$

\begin{tabular}{|c|c|c|c|c|c|c|c|}
\hline & \multicolumn{2}{|c|}{ Non-users } & \multirow{2}{*}{\multicolumn{2}{|c|}{$\frac{\text { Website users }}{(n=18-24)}$}} & \multirow{2}{*}{\multicolumn{2}{|c|}{$\frac{\text { Login users }}{(n=68-80)}$}} & \multirow[t]{3}{*}{$P^{1}$} \\
\hline & \multicolumn{2}{|c|}{$(n=52-81)$} & & & & & \\
\hline & T0 & $\mathrm{T} 1$ & TO & $\mathrm{T} 1$ & TO & T1 & \\
\hline Satisfaction with rheumatologist ${ }^{2}$ & $22.3(2.3)$ & $22.6(2.3)$ & $21.9(2.1)$ & $23.0(1.6)$ & $22.4(2.1)$ & $22.6(2.0)$ & n.s. \\
\hline Satisfaction with nurse ${ }^{2}$ & $22.5(2.4)$ & $22.6(2.4)$ & $21.9(2.1)$ & $23.0(2.0)$ & $22.4(2.5)$ & $22.8(2.0)$ & n.s. \\
\hline Trust in the rheumatologist ${ }^{3}$ & $17.1(2.2)$ & $17.5(2.3)$ & $16.8(2.3)$ & $16.3(3.2)$ & $17.3(2.3)$ & $17.4(2.3)$ & n.s. \\
\hline Perceived self-efficacy in patient-provider communication ${ }^{4}$ & $21.3(3.1)$ & $21.8(3.3)$ & $20.7(2.8)$ & $20.9(3.2)$ & $21.2(3.5)$ & $21.3(3.2)$ & n.s. \\
\hline Illness perception & & & & & & & \\
\hline Personal control $^{5}$ & $18.8(2.8)$ & $18.9(3.4)$ & $19.0(2.9)$ & $19.4(3.1)$ & $19.3(3.3)$ & $19.6(3.9)$ & n.s. \\
\hline IIIness coherence ${ }^{4}$ & $16.1(3.1)$ & $16.2(3.6)$ & $16.5(3.6)$ & $17.7(3.8)$ & $17.5(3.7)$ & $17.4(3.5)$ & n.s. \\
\hline Treatment control $^{4}$ & $18.8(2.6)$ & $18.5(3.0)$ & $18.9(3.1)$ & $18.8(2.0)$ & $19.0(2.6)$ & $19.2(2.5)$ & n.s. \\
\hline Medication adherence ${ }^{6}$ & $6.5(1.4)$ & $6.7(1.2)$ & $5.5(1.3)$ & $6.5(1.3)$ & $6.3(1.5)$ & $6.5(1.2)$ & n.s. \\
\hline
\end{tabular}

${ }^{1}$ Analyses of Covariance; ${ }^{2}$ possible range: $6-24 ;{ }^{3}$ possible range: $5-20 ;{ }^{4}$ possible range: $5-25 ;{ }^{5}$ possible range: $6-30 ;{ }^{6}$ possible range: 1 (severely lacking adherence) -8 (perfect adherence).

score on the scale. Our results showed that $45 \%$ of the respondents scored the highest possible score on satisfaction with the rheumatologist, $52 \%$ on satisfaction with the nurse, $30 \%$ on trust in the rheumatologist and $29 \%$ on self-efficacy in the patient-provider communication. This shows that room for improvement on these measures was limited in our sample. Additionally, 56\% of the respondents had a score of 7 on medication adherence, with a highest possible score of 8 ; while this cannot be defined as a ceiling effect, room for improvement was limited on this outcome as well.

\section{Discussion}

Our study shows that there is a large interest among RA patients for a hospital-based rheumatology web portal. More than half of the respondents with Internet access logged in to the portal, to view their personal data. Of all the non-users in our sample, only $10 \%$ reported not wanting to use the portal because they were not interested. The other non-users either had no access to the Internet, or intended to visit the portal in the future. Reported usage from other studies on patient web portals with EMR access varies from only 6\% [32] to up to $86 \%$ [33]. However, it is difficult to compare the results of our study with these previous studies, as they differ widely in types of patient groups and in the additional services that were provided. Notable is that the portion of patients in our study that logged in to view their personal information is much larger than the portion that only viewed the general information on the patient web portal. Previous studies have also found that personal information, and especially laboratory results, are more useful than general information to patients with chronic conditions [13]. Concordantly, we can conclude that our portal with EMR access foresees in a need in these patients.
One of the aims of our study was to investigate determinants of use of the application. Out of all the included variables, only age was a significant predictor of general portal use: younger patients were more inclined to visit the portal. This corresponds to what was found in much of the previous research on predictors of use of online applications $[16,17,34]$. Because the mean age of our sample was 62, our data shows that older generations in the Netherlands actively use the Internet, the proportion of which will only increase in the upcoming generations. As expected, self-perceived Internet skills and amount of Internet use significantly predicted logging in on the patient web portal. Previous research focusing on adoption of patient web portals, has also found that computer literacy can be a barrier in the uptake of health technologies $[35,36]$. It would be interesting to study whether more active encouragement and guidance from care providers towards patients with low (e)health literacy would affect their interest and use of the application.

Our portal was designed with a strong focus on the enduser, in which patients were invited to be actively involved in the determination of the content and the design of the portal. Also, together with rheumatology care providers, we made an effort to present up to date DAS28 and lab results in a clear overview. Previous studies have shown that care providers are hesitant about patient EMR access because it could confuse patients $[21,37,38]$, but our results show that patients found the login part of the portal usable and understandable. Additionally, "mistakes" that were found in the patient-accessible EMR only concerned data that was slightly outdated and the few patients that experienced this handled these issues very well. While it should be noted that our patient-accessible EMR contained only a selection from the full medical records, it seems that when implemented carefully, expected drawbacks hardly occur. This confirms that a user-centered 
design is beneficial in the development of patient web portals. Further research should also explore care providers' experiences with patients who use the portal, and the changes in work flow that they perceive, in order to determine to what extent the patient web portal changes health care processes.

Evaluating the impact of the patient web portal, we could not find significant differences over time in empowerment. Nevertheless, patients that logged in to the portal did report to perceive a larger involvement in, and understanding of, their treatment. Patients also reported that using the login part of the portal improved their knowledge of their disease and increased their capability to understand their care providers. Most patients reported using the login service prior to a consultation, which could indicate that they used it to prepare for the conversation with their doctor or nurse [34,38]. Two recent systematic reviews on the effects of patient web portals with EMR access show that only a few other studies have included empowerment-related outcomes into their evaluations, with small and inconclusive results [13,10]. Tuil et al. [9], who conducted a study among patients undergoing IVF treatment, could not detect any enhancement in patient empowerment over time either. Ross et al. [15], who evaluated a portal with EMR access among patients with congestive heart failure, found improvements in medication adherence and a small trend in increased self-efficacy and satisfaction with patient-provider communication. In our study, the lack of change over time might be explained by the timeframe between both measurements. If the posttest had been assessed at a later moment in time, through which patients could have used the portal more regularly, (especially in relation to more consultations) effects would perhaps have been more visible. Moreover, the instruments used might not have been responsive enough to measure a difference. Large ceiling effects were found on the outcomes before using the patient web portal, leaving little room for improvement.

When interpreting these results, we should take note of some limitations. First, a response bias might have occurred. It is conceivable that patients who completed the questionnaires were already satisfied and involved patients, preempting any measurable increase of the empowerment-related outcomes. Such response bias should also be mentioned in the light of the usage, satisfaction and perceived effect of the portal; it is possible that patients who were more interested in online information and support in the first place were more intended to use the portal, to complete our surveys and to value the portal positively. Second, this study relied on self-report measurements; however we are not sure if patients are able and motivated to make reliable assessments of their behavior. Future studies using less subjective measures, such as observations of doctor-patient communications or pill-counting boxes, could reveal whether patients are actually more knowledgeable about their disease, better able to speak up to their doctor and more adherent to medication. Also, observing patients' portal usage during assignments might provide a more valuable assessment of actual web portal usability. From a previous study, it appeared that patients are not always aware of the mistakes they make when using the Internet for healthrelated purposes [39]. To further enhance the use and the impact of the portal, more attention might be paid to its content during consultations, so that patients might learn how to use the information from their records for their own benefit $[40,41]$.

\section{Conclusions}

In conclusion, a hospital-based rheumatology patient web portal with EMR access offers rheumatoid arthritis patients usable and understandable access to personal information. While the actual impact on patient empowerment is difficult to measure, a large portion of patients does feel more informed and involved in their own treatment due to the portal.

\section{Competing interests}

The authors declare that they have no competing interests.

\section{Authors' contributions}

RV carried out the evaluation study, analyzed the data and drafted the manuscript. CD and ET participated in the design of the study and helped to draft the manuscript. HV, WD enabled the study, helped with data acquisition and amended the manuscript in the final stage. ML enabled the study, participated in the design and amended the manuscript in the final stage. All authors read and approved the final manuscript.

\section{Acknowledgements}

We would kindly like to thank the participants of the surveys, and the rheumatologists and rheumatology secretariat of Medisch Spectrum Twente, Enschede, for their participation and contribution to this study. This study was supported by an unrestricted educational grant from Pfizer Inc. This funding source had no involvement in data collection, analysis, the preparation of this manuscript or the decision to submit the article for publication.

Unrestricted educational grant supporter: Pfizer Inc.

\section{Author details}

Department of Psychology, Health \& Technology, University of Twente, Citadel H423, P.O. Box 2177500 AE, Enschede, The Netherlands. ${ }^{2}$ Arthritis Centre Twente, Medisch Spectrum Twente, Enschede, the Netherlands.

Received: 12 August 2013 Accepted: 12 March 2014

Published: 26 March 2014

\section{References}

1. Carlin CS, Christianson JB, Keenan P, Finch M: Chronic illness and patient satisfaction. Health Serv Res 2012, 47(6):2250-2272

2. Arvidsson S, Bergman S, Arvidsson B, Fridlund B, Tingström P: Psychometric properties of the Swedish Rheumatic Disease Empowerment Scale, SWE-RES-23. Musculoskelet Care 2012, 10(2):101-109.

3. Ruland CM, Andersen T, Jeneson A, Moore S, Grimsbø GH, Børøsund E, Ellison MC: Effects of an Internet support system to assist cancer patients in reducing symptom distress. Cancer Nurs 2013, 36(1):6-17.

4. Wagner EH, Austin BT, Davis C, Hindmarsh M, Schaefer J, Bonomi A: Improving chronic illness care: translating evidence into action. Health Aff 2001, 20:64-78. 
5. Buntin MB, Burke MF, Hoaglin MC, Blumenthal D: The benefits of health information technology: a review of the recent literature shows predominantly positive results. Health Affair 2011, 30(3):464-471.

6. Fisher B, Fitton R, Poirier C, Stables D: Patient record access - the time has come! Br J Gen Pract 2007, 57(539):507-511.

7. Eysenbach G: Medicine 2.0: social networking, collaboration, participation, apomediation, and openness. J Med Internet Res 2008, 10:e22.

8. Gravis G, Protière C, Eisinger F, Boher JM, Tarpin C, Coso D, Cappiello M Camerlo J, Genre D, Viens P: Full access to medical records does not modify anxiety in cancer patients. Cancer 2011, 117(20):4796-4804

9. Tuil WS, Verhaak CM, Braat DDM, de Vries Robbé PF, Kremer JAM: Empowering patients undergoing in vitro fertilization by providing Internet access to medical data. Fertil Steril 2007, 88(2):361-368.

10. Ammenwerth $E$, Schnell-Inderst $P$, Hoerbst A: The impact of electronic patient portals on patient care: a systematic review of controlled trials. J Med Internet Res 2012, 14(6):e162.

11. Chaudhry B, Wang J, Wu S, Maglione M, Mojica W, Roth E, Morton SC, Shekelle PG: Systematic review: impact of health information technology on quality, efficiency, and costs of medical care. Ann Intern Med 2006, 144(10):742-752

12. Winkelman WJ, Leonard KJ, Rossos PG: Patient-perceived usefulness of online electronic medical records: employing grounded theory in the development of information and communication technologies for use by patients living with chronic illness. J Am Med Inform Assoc 2005, 12:306-314.

13. Urowitz S, Smith K, Alkazaz N, Apatu E, Quartey NK, Wiljer D: Patient accessible electronic health records for the chronically ill: a review of the literature. J Hosp Admin 2012, 1(2):64-72.

14. Goldberg HI, Ralston JD, Hirsch IB, Hoath Jl, Ahmed Kl: Using an Internet comanagement module to improve the quality of chronic disease care. Jt Comm J Qual Patient Saf 2003, 29(9):443-451.

15. Ross SE, Moore LA, Earnest MA, Wittevrongel L, Lin CT: Providing a webbased online medical record with electronic communication capabilities to patients with congestive heart failure: randomized trial. J Med Internet Res 2004, 6(2):e12.

16. Grant RW, Wald JS, Schnipper JL, Gandhi TK, Poon EG, Orav EJ, Williams DH, Volk LA, Middleton B: Practice-linked online personal health records for type 2 diabetes mellitus: a randomized controlled trial. Archives Internal Med 2008, 168(16):1776-1782.

17. Or CKL, Karsh B: A systematic review of patients acceptance of consumer health information technology. J Am Med Inform Assoc 2009, 16:550-560.

18. Norman CD, Skinner HA: eHealth literacy: essential skills for consumer health in a networked world. J Med Internet Res 2006, 8(2):e9.

19. Van der Vaart R, Drossaert CHC, Taal E, Van de Laar MAFJ: Experiences and preferences of patients with rheumatic diseases regarding an interactive health communication application. Saint Martin: Proceedings of the 2nd eTELEMED International Conference on eHealth, Telemedicine, and Social Medicine; 2010:64-71. doi: 10.1109/eTELEMED.2010.16.

20. Van der Vaart R, Drossaert CHC, Taal E, Van de Laar MAFJ: Patient preferences for a hospital based rheumatology Interactive Health Communication Application, and factors associated with these preferences. Rheumatology 2011, 50(9):1618-1626.

21. Van der Vaart R, Drossaert CHC, Taal E, Van de Laar MAFJ: Giving rheumatology patients online home access to their electronic medical record (EMR): advantages, drawbacks and preconditions according to care providers. Rheumatol Int 2012. ePub ahead of print.

22. Van Gemert-Pijnen JEWC, Nijland N, Van Limburg M, Eng B, Ossebaard HC, Kelders SM, Eysenbach G, Seydel ER: A holistic framework to improve the uptake and impact of eHealth technologies. J Med Internet Res 2011, 13(4):e111.

23. Ishikawa $H$, Takeuchi T, Yano E: Measuring functional, communicative, and critical health literacy among diabetic patients. Diabetes Care 2008, 31(5):874-879

24. Van der Vaart R, Drossaert CHC, Taal E, Ten Klooster PM, Hilderink-Koertshuis RTE, Klaase JM, Van de Laar MAFJ: Validation of the Dutch functional, communicative and critical health literacy scales. Pat Educ Couns 2012 ePub ahead of print.

25. Van Campen C, Sixma HJ, Kerssens JJ, Peters L, Rasker JJ: Assessing patients' priorities and perceptions of the quality of health care: the development of the quote-rheumatic-patients-instrument. $\mathrm{Br} J$ Rheumatol 1998, 37(4):362-368
26. Ommen O, Janssen C, Neugebauer E, Bouillon B, Rehm K, Rangger C, Erli HJ, Pfaff H: Trust, social support and patient type-Associations between patients perceived trust, supportive communication and patients preferences in regard to paternalism, clarification and participation of severely injured patients. Patient Educ Couns 2008, 73(2):196-204.

27. Maly RC, Frank JC, Marshall GN, DiMatteo MR, Reuben DB: Perceived Efficacy in Patient-Physician Interactions (PEPPI): validation of an instrument in older persons. J Am Geriatr Soc 1998, 46:889-894.

28. Ten Klooster PM, Oostveen JCM, Zandbelt LC, Taal E, Drossaert CHC, Harmsen EJ, Van de Laar MAFJ: Further validation of the 5-item Perceived Efficacy in Patient-Physician Interactions (PEPPI-5) scale in patients with osteoarthritis. Patient Educ Couns 2012, 87(1):125-130.

29. Moss-Morris R, Weinman J, Petrie KJ, Horne R, Cameron LD, Buick D: The revised IIIness Perception Questionnaire (IPQ-R). Psychol Health 2002, 17(1):1-16

30. Morisky DE, Green LW, Levine DM: Concurrent and predictive validity of a self-reported measure of medication adherence. Med Care 1986 24(1):67-74

31. Morisky DE, Ang A, Krousel-Wood M, Ward HJ: Predictive validity of a medication adherence measure in an outpatient setting. $J$ Clin Hypertens 2008, 10(5):348-354.

32. Zhou Y, Garrido T, Chin H, Wiesenthal A, Liang L: Patient access to an electronic health record with secure messaging: impact on primary care utilization. Am J Manag Care 2007, 13(7):418-424.

33. Bhavnani V, Fisher B, WinWeld M, Seed P: How patients use access to their electronic GP record: a quantitative study. Fam Pract 2010, 0:1-7.

34. Kahn JS, Hilton JF, Van Nunnery T, Leasure S, Bryant KM, Hare CB, Thom DH: Personal health records in a public hospital: experience at the HIV/AIDS clinic at San Francisco General Hospital. J Am Med Inf Assoc 2010, 17(2):224-228.

35. Greenhalgh T, Hinder S, Stramer K, Bratan T, Russell J: Adoption, non-adoption, and abandonment of a personal electronic health record: case study of HealthSpace. BMJ 2010, 341:c5814.

36. Zickmund SL, Hess R, Bryce CL, McTigue K, Olshansky E, Fitzgerald K, Fischer GS: Interest in the use of computerized patient portals: role of the provider-patient relationship. J Gen Intern Med 2008, 23(Suppl 1):20-26.

37. Ross SE, Todd J, Moore LA, Beaty BL, Wittevrongel L, Lin CT: Expectations of patients and physicians regarding patient-accessible medical records. J Med Internet Res 2005, 7:e13.

38. Wiljer D, Leonard K, Urowitz S, Apatu E, Massey C, Kwarley QN: The anxious wait: assessing the impact of patient accessible EHRs for breast cancer patients. BMC Med Inform Decis Mak 2010, 10(1):46.

39. Van der Vaart R, Drossaert CHC, De Heus M, Taal E, Van de Laar MAFJ: Measuring actual eHealth literacy among patients with rheumatic diseases: a qualitative analysis of problems encountered using Health 1.0 and Health 2.0 applications. J Med Internet Res 2013, 15:e27.

40. Ralston JD, Hirsch IB, Hoath J, Mullen M, Cheadle A, Goldberg HI: Web-based collaborative care for type 2 diabetes: a pilot randomized trial. Diabetes Care 2009, 32(2):234-239.

41. Osborn CY, Satterwhite Mayberry L, Mulvaney SA, Hess R: Patient web portals to improve diabetes outcomes: a systematic review. Curr Diab Rep 2010, 10(6):422-435

doi:10.1186/1471-2474-15-102

Cite this article as: van der Vaart et al:: Impact of patient-accessible electronic medical records in rheumatology: use, satisfaction and effects on empowerment among patients. BMC Musculoskeletal Disorders 2014 15:102 